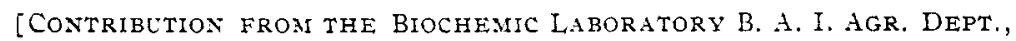
WASHINGTON, D. C.

\title{
THE COMPOSITION OF THE TUBERCLE BACILLI DERIVED FROM VARIOUS ANIMALS. ${ }^{1}$
}

BY E. A. DE SCHWEINITZ AND M, DORSET.

Received fanunry' 17, 1903 .

Continting our rork as published in this Journal, 17,605; 18,$449 ; 20,618$, we have submitted to examination tubercle bacilli from various sources; namely, bovine bacilli, swine bacilli, horse bacilli, avian bacilli, attenuated human bacilli and virulent human bacilli.

In preparing these germs for analyses all were grown upon liquid media. After the cultures had been allowed to develop for a sufficient length of time, they were all filtered in the same way, washed in the same way so as to remove from the germs themselves, any mechanically adherent culture media, and necessarily at the same time, a large portion of the water-soluble matter. The germs, subsequently dried in zacuo, were submitted to analysis, first by extracting with ether, then with alcohol and then with chloroform. A comparison of the amounts of these extracts shows that the largest percentage of fat was obtained from the attenuated human bacilli, and from the others in the following order: Horse, virulent human, bovine, avian, swine.

In our earlier article upon the mineral constituents of the tubercle bacilli, published in this Journal, 18, 449, the percentage of phosphoric pentoxide was found to be a little over 55 in the human germ. As will be noted in Table II, the percentage of phosphoric pentoxide in these human germs was found to be, in the virulent, over 60 per cent., in the attenuated over 70 per cent. In comparing these figures with the earlier results, it should be remembered that the germs used for obtaining the earlier data were grown upon the ordinary glycerine media to which no phosphates had been added, while all of the present germs were grown upon a medium intentionally rich in phosphates. The amount of material available for the phosphoric pentoxide determinations here reported was also small, so that there may be some slight error due to manipulation, but allowing for these facts, it is very evident that all of these tubercle bacilli

\footnotetext{
1 Read at the Washington meeting of the American Chemical Society.
} 
are voracious consumers of phosphoric oxide, in which property they correspond to a great many other plants.

Aronson's assumption that the extractive matter of the tubercle bacilli was very largely fatty acids, a conclusion which does not follow from the methods that he has reported in his article, led us to make some preliminary determinations of the possible free acid present in our various extracts. Kresling concluded that the chloroform extract of the human tubercle bacilli contains about 14 per cent. of free fatty acid. Our determinations of the possible free fatty acid were based upon the acid value as secured by titration with $\mathrm{N} /$ ro sodium hydroxide. The results are recorded in Table III.

The acid value was determined both in the ether and alcohol extracts separately. The total acid value noted in Table III shows that the highest acid value was obtained from the virulent human and the others in the following order: Swine, attenuated human, avian, bovine and horse. In the last column are given the total percentages of the free acids in the whole germ counted as oleic acid. The acids were all calculated as oleic for the purpose of making a satisfactory basis for comparison.

Until we have completed the determinations of the exact character of the ether, alcohol and chloroform extracts obtained from these various bacilli, which are in progress at present, much speculation in regard to the relation of the composition of the germ to its character and virulence is not warranted. It is interesting to note, however, that the percentage of alcohol extract obtained from the avian bacilli is very much greater than that obtained from any of the other germs, while the percentage of chloroform extract in the bovine bacilli and virulent human bacilli is almost exactly the same, there being but little chloroform extract obtained from the horse, swine and avian germs, while a considerably larger amount is secured from the attenuated human germ. The variation in the amount of ether extract has a'zeady been noted. The results certainly indicate that as there is a variation in the morphology of tubercle bacilli derived from different sources, depending upon their surroundings, so there is a variation in the composition of the germ cells themselves. They show, further, a point which should be especially emphasized, that there is a greater difference between the two human germs, the 
one attenuated, non-pathogenic for guinea pigs, the other almost as pathogenic for guinea pigs as the bovine germ, than there is between the virulent human and the bovine and horse bacilli. It is certainly not an unwarranted assumption that possibly this loss of virulence in the human germ is due to the fact that the bacilli have acquired through their prolonged saprophytic existence, and their consequent immunity from the attacks of phagocytes and other protective substances of the animal body, the property of producing smaller amounts of poisonous substances, while in the case of the virulent human bacilli, the bovine, horse and swine germs, which do not produce nearly so large an amount of harmless fatty substances, and consequently contain a lower percentage of extractive matter, the relative amount of poisonous proteid profucerl is greater. That this proteid matter, belonging to the class of nucleoproteids, as was already pointed out by ourselves in 1895 in the article above referred to, is one of the principal poisons of the tubercle bacilli, has been well demonstrated; and if the bacilli are able to produce larger amounts of these poisonous substances, it would necessarily follow that they are much more virulent. A further study of these proteid substances is in progress, as well as the identification of the free fatty acids, fats, waxes and other extractive material.

As pointed out by the writers in $1897,{ }^{1}$ there is present in the cultures of human bacilli a very virulent acid-like necrotic substance readily soluble in water. This substance, as well as those of a similar nature, was necessarily extracted in the preparation of the germs for analysis, and hence does not come into consideration in this report.

() ur results here recorded indicate the relationship between the tubercle bacilli derived from various sources and emphasize the difference between attenuated and virulent human tubercle bacilli. It must be remembered that these analyses were only upon one representative of each of the different bacilli, yet the results in the human germs correspond so closely with those obtained in I 895 and also those reported by other workers, that we can assume a like composition for the bacilli obtained from similar sources.

\footnotetext{
1 De schweinitz and Dorset: Centrbl. für Bakt. u. Parasit., Ahst. I, 22, 209 (1897).
} 


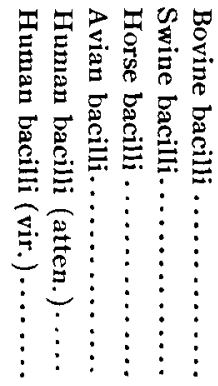

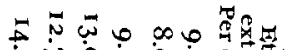

尊

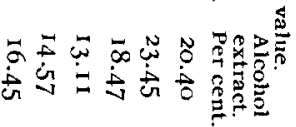

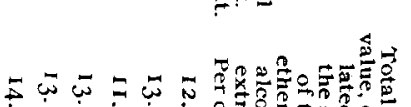

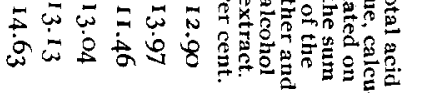

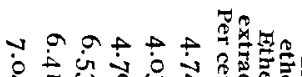

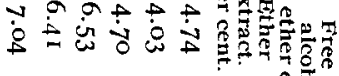

कن

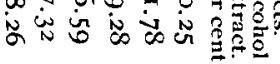

vagur o o

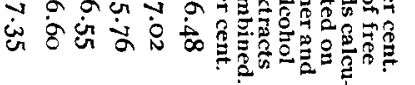

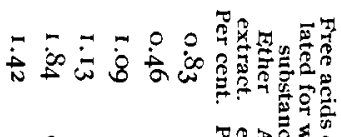

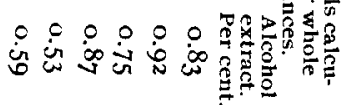

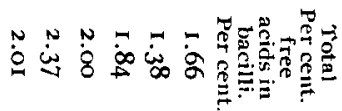

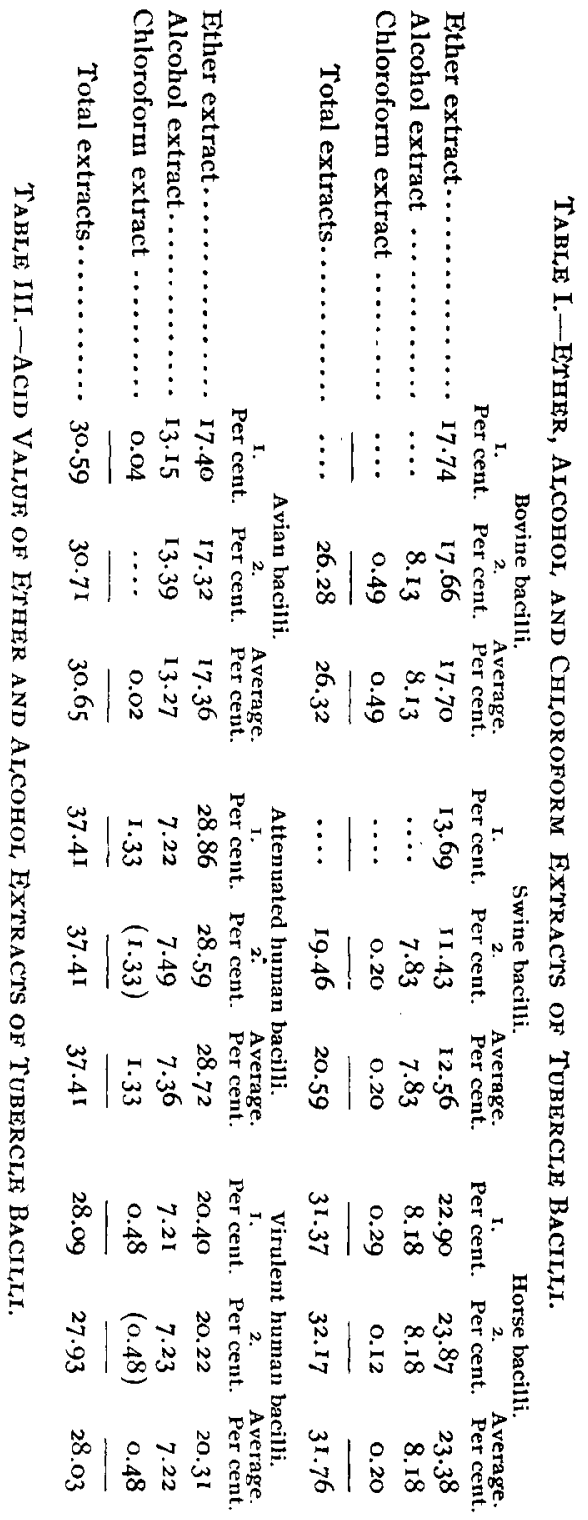


Table II. - Ash and Phosphorus in Ttbercle Bacitri. ${ }^{1}$

\begin{tabular}{|c|c|c|c|c|}
\hline & $\begin{array}{l}\text { Moisture. } \\
\text { Per cent. }\end{array}$ & $\begin{array}{c}\text { Ash } \\
\text { Percent. }\end{array}$ & $\begin{array}{l}P_{2} \mathrm{O}_{\text {in }} \text { ind } \\
\text { bacilli. } \\
\text { Per cent. }\end{array}$ & $\begin{array}{l}\mathrm{P}_{2} \mathrm{O}_{5} \text { int } \\
\text { ash. } \\
\text { Per cent }\end{array}$ \\
\hline \multirow{2}{*}{ Bovine bacilli. } & $\int 2.42$ & 2.66 & I. $5^{6}$ & $5^{8.54}$ \\
\hline & 2.48 & 2.67 & I. 55 & $5^{8.04}$ \\
\hline \multirow{2}{*}{ Swine bacilli. . } & 2.26 & 2.37 & 1.30 & 55.00 \\
\hline & 2.06 & $2.3 \mathrm{I}$ & 1.31 & 56.48 \\
\hline \multirow{2}{*}{ Horse bacilli. } & 2.27 & 3.63 & 2.07 & 55.68 \\
\hline & 2.42 & 3.55 & 2.02 & $55 \cdot 40$ \\
\hline \multirow{2}{*}{ Avian } & $\int 2.40$ & 3.96 & 2.22 & 55.98 \\
\hline & $\ldots$ & 3.94 & 2.19 & 55.63 \\
\hline \multirow{2}{*}{ Human bacilli (atten.) } & 2.67 & 2.44 & I. 79 & 73.49 \\
\hline & $2.5^{8}$ & $2.3 I$ & 1.71 & $74 \cdot 3^{8}$ \\
\hline \multirow{2}{*}{ Human bacilli } & $\{3.95$ & 3.94 & 2.50 & 63.47 \\
\hline & 13.70 & 3.92 & 2.39 & 60.90 \\
\hline
\end{tabular}

'Determinations by James A. Enery.

[CONTRIBUTION FROM THE LABORATORY OF THE BUREAC OF INTERNAL REVENUE, U.S. TREASUR X DEPARTMENT.]

\section{THE COMPOSITION OF PROCESS OR RENOVATED BUTTER.'}

BY ChARLESA. CRAMPTON.

Recelvel , lanuary 5,1903

THE Act of May 9, I902, makes this product, as specifically defined therein, subject to Federal control, placing its production, transportation and sale under restrictions similar to those imposed upon oleomargarine, which product is also made the subject of new legislation by the same act.

Without entering into detail concerning the provisions of the new law, its main features may be briefly stated, as follows: It defines two classes of oleomargarine, one taxable at $1 / 4$ cent per pound, and the other at ro cents per pound, and three classes of butter. Of the latter, one class is normal or statutory butter, defined for purposes of comparison, and exempt, of course, from taxation or supervision; one class is "process or renovated butter," taxable at $1 / 4$ cent per pound, the same rate as that laid upon oleomargarine free from artificial coloration; and the third class is "adulterated butter," subject to a tax of Io cents per pound, the same rate as artificially colored oleomargarine.

The sale of renovated butter is not so closely regulated as that of oleomargarine, as no special tax is required from wholesale or retail dealers, so that government control does not follow it to the

1 Read at the washington meeting of the American Chemica! society. 